\title{
PEMASARAN TERNAK SAPI POTONG DI KABUPATEN OGAN KOMERING ILIR, SUMATERA SELATAN
}

\section{BEEF CATTLE MARKETING IN OGAN KOMERING ILIR REGENCY, SOUTH SUMATERA}

\author{
Jaka Sumitra $^{1 *}$, Tri Anggraeni Kusumastuti ${ }^{2}$, dan Rini Widiati ${ }^{2}$ \\ ${ }^{1}$ Dinas Peternakan Kabupaten Ogan Komering Ilir, Jl. Letnan Darna Jambi, Kayuagung, Kabupaten Ogan Komering \\ Ilir, Sumatera Selatan, 30611 \\ ${ }^{2}$ Fakultas Peternakan, Universitas Gadjah Mada, Jl. Fauna No. 3, Bulaksumur, Yogyakarta, 55281
}

\section{INTISARI}

Penelitian ini bertujuan untuk mengidentifikasi saluran pemasaran, menghitung margin pemasaran, berat taksir dan berat timbang ternak, gross margin peternak, pedagang desa, pedagang besar dan jagal serta menentukan kebijakan strategi pemasaran. Lokasi penelitian dipilih secara purposive sampling di tiga Kecamatan yaitu Lempuing, Lempuing Jaya dan Mesuji Raya, Kabupaten Ogan Komering Ilir. Penelitian dilaksanakan bulan Juli sampai dengan Agustus 2011. Responden adalah peternak sebanyak 60 orang, pedagang desa 15 orang, pedagang besar dan jagal masingmasing 5 orang. Obyek penimbangan adalah ternak sapi yang dijual di tingkat peternak, pedagang desa, pedagang besar masing-masing 60 ekor (30 jantan dan 30 betina) dan jagal 30 ekor jantan. Metode yang digunakan adalah survei dengan pengamatan langsung dan wawancara kepada responden. Analisis deskriptif untuk margin pemasaran dan analisis kuantitatif untuk membandingkan berat taksir dengan berat timbang ternak dengan uji t. Selanjutnya membandingkan gross margin peternak, pedagang desa, pedagang besar dan jagal menggunakan one way ANOVA yang dilanjutkan dengan Duncan Multiple Range Test (DMRT). Hasil penelitian diperoleh ada 3 saluran pemasaran, saluran I dari peternak ke jagal melalui 2 pedagang yaitu pedagang desa dan pedagang besar, saluran II dari peternak ke jagal melalui 1 pedagang yaitu pedagang desa dan saluran III dari peternak langsung ke jagal. Margin pemasaran saluran I Rp2.562.835,00/ekor, saluran II Rp930.979,00/ekor dan saluran III Rp0,00/ekor. Tidak ada perbedaan nyata antara berat taksir sapi yang dipasarkan dan berat timbang. Terdapat perbedaan gross margin yang nyata $(\mathrm{P}<0,05)$ antara peternak (Rp873.833,00/ekor) dengan pedagang desa (Rp1.783.213,00\%/ekor) dan jagal (Rp3.256.898,00\%/ekor), sedangkan dengan pedagang besar (Rp326.736,00/ekor) tidak berbeda. Kebijakan strategi pemasaran untuk meningkatkan gross margin peternak melalui kebijakan saluran pemasaran yaitu memilih saluran yang paling menguntungkan peternak, kebijakan harga yaitu menentukan standar harga jual ternak dan kebijakan gross margin yaitu memberikan harga input dan output yang menguntungan peternak.

(Kata kunci: Saluran pemasaran, Sapi potong, Margin pemasaran, Gross margin)

\section{ABSTRACT}

This research was aimed to identify the marketing channels, to calculate the marketing margins, to predict weight and scale weight of cattle, gross margin of farmers, village traders, wholesalers, butchers and to determine the marketing strategy policies. The research locations were selected by purposive sampling in three districts namely Lempuing, Lempuing Jaya and Mesuji Raya in Ogan Komering Ilir. The study was conducted from July to August 2011. The respondents were 60 farmers, 15 village traders, wholesalers and butchers with five (5) respondents each. Cattle weighing were done at farmers level of cattle sold, village traders, wholesalers as much as for each level 60 cattle (30 bulls and $30 \mathrm{cow})$ and butchers level 30 males. The methods used were surveys with direct observations and interviews with respondents and weighing of livestock. The analysis used was descriptive analysis for the marketing margins and quantitative analysis, the t-test was used to compare the predicted and scale weight of beef cattle. Gross margins of farmers, village traders, wholesalers and butchers were analysed using one way ANOVA followed by Duncans' Multiple Range Test (DMRT) for significant differences. The results showed that there were three (3) marketing channels, the $1^{\text {st }}$ channel was the farmer to butcher with two brokers namely village traders and wholesalers, the $2^{\text {nd }}$ channel from farmers to butcher with one broker namely village traders and $3^{\text {rd }}$ channel from farmers directly to the butcher. The first channel recorded a marketing margin of Rp2,562,835.00/head the $2^{\text {nd }}$ channel recorded Rp930,979.00/head and $3^{\text {rd }}$ channel recorded Rp0,00/head. No significant difference between the predicted weigh an cattle weigh measured on scale. The gross margin had significant difference $(P<0.05)$ between the farmers $\left(\right.$ Rp $\left.873,833.00^{a} / h e a d\right)$ with village traders and butchers recording of $\left(R p 1,783,213.00^{b} / h e a d\right)$ and (Rp3,256,898.00/head) respectively, whereas there was no difference with wholesalers (Rp326,736.00a/head). Marketing policy strategies to improve farmer gross margin through the selection of the most profitable marketing

\footnotetext{
* Korespondensi (corresponding author):

Telp. +6281373945424

E-mail: jokomitro@gmail.com
} 
channels, pricing policies that determine the price of livestock standards and policies of the gross margin provides input and output prices which favorable for the farmers.

(Key words: Marketing channels, Beef cattle, Marketing margin, Gross margin)

\section{Pendahuluan}

Pemasaran pada prinsipnya merupakan proses kegiatan penyaluran produk yang dihasilkan oleh produsen agar dapat sampai kepada konsumen. Bagi produsen sapi potong, baik perusahaan peternakan maupun peternakan rakyat pemasaran mempunyai peran yang penting. Setelah produk dalam hal ini ternak dihasilkan peternak pasti menginginkan ternaknya cepat sampai dan diterima oleh konsumen. Menurut Rianto dan Purbowati (2010), peternak harus melewati beberapa kegiatan pemasaran antara lain pengumpulan informasi pasar, penyimpanan, pengangkutan dan penjualan produk.

Sapi potong merupakan komoditas subsektor peternakan yang sangat potensial. Hal ini dapat dilihat dari tingginya permintaan akan daging. Pada tahun 2008 permintaan daging di Indonesia sebanyak 385.035 ton dan baru terpenuhi sebanyak 249.925 ton (Rianto dan Purbowati, 2010). Secara nasional Indonesia masih belum mampu mencukupi kebutuhan permintaan daging sapi tersebut, sehingga salah satu cara untuk mengatasi kekurangan daging tersebut maka pemerintah membuka kran import sapi hidup maupun daging sapi (beku) dari negara lain. Langkah yang diambil pemerintah untuk mengatasi hal tersebut adalah dengan menetapkan program kecukupan daging 2014. Dalam mencapai program tersebut, diperlukan terobosan yang efektif dan dukungan yang nyata dari pemerintah dan masyarakat, khususnya yang bergerak di bidang usaha sapi potong. Jika dilihat lebih jauh lagi, kondisi peternakan sapi potong saat ini belum menggembirakan. Fenomena ini dapat dilihat dari pertumbuhan populasi ternak sapi potong yang masih rendah yaitu sebesar 5,33\%/tahun atau kurang lebih 655.500 ekor/tahun dari populasi 9.867.522 ekor pada tahun 2003 menjadi 14.805.053 ekor pada tahun 2011 (Anonimus, 2011).

Melihat fenomena dan kenyataan di atas, masyarakat peternakan di Kabupaten Ogan Komering Ilir memanfaatkan kesempatan tersebut sebagai peluang usaha peternakan yang baik untuk ditumbuhkembangkan, terlebih secara komparatif peternakan sapi potong merupakan salah satu subsektor unggulan dari enam subsektor unggulan yang ada. Peternakan rakyat sangat erat hubungannya dengan potensi sumberdaya alam dan manusia. Potensi ekonomi subsektor peternakan dapat dimanfaatkan secara berkelanjutan dan mampu memberikan kontribusi dalam meningkatkan kemakmuran rakyat, sedangkan di sisi lain ada tantangan besar yang harus dihadapi seperti keterbatasan modal, rendahnya wawasan agribisnis dan tatalaksana pemeliharaan yang masih tradisional untuk segera diatasi. Hal ini sudah merupakan isu hangat yang sedang berkembang di masyarakat Ogan Komering Ilir sebagai ungkapan harapan dan keinginan mendayagunakan sumberdaya alam yang tersedia.

Subsektor peternakan di Kabupaten Ogan Komering Ilir dapat dijadikan basis pengembangan usaha rakyat karena subsektor ini cukup menjanjikan sebagai alternatif upaya menciptakan citacita pembangunan yang memberdayakan perekonomian rakyat dan subsektor ini sangat menyentuh langsung masyarakat bawah. Peternakan rakyat merupakan usaha peternakan yang sangat potensial untuk dikembangkan dan memegang peranan yang besar bagi perkembangan populasi ternak khususnya ternak sapi potong dan menyumbang pendapatan keluarga yang dominan setelah pertanian tanaman pangan. Usaha peternakan sapi potong di Kabupaten Ogan Komering Ilir kurang lebih 90\% merupakan peternakan rakyat yang memliki ternak antara 1 sampai 3 ekor (Anonimus, 2009). Peternak di dalam melaksanakan usahanya selalu menghadapi permasalahan serius yang sangat mempengaruhi gross margin-nya yaitu masalah pemasaran. Pola pemasaran ternak sapi potong di Kabupaten Ogan Komering Ilir masih bersifat tradisional karena peternak tidak menjual langsung sapinya ke pasar hewan atau pedagang besar melainkan ke pedagang desa. Peran pedagang desa masih dirasakan sangat membantu peternak, sehingga pedagang desa tidak mungkin dihilangkan dari saluran pemasaran, namun peternak dihadapkan pada posisi tawar yang lemah, mereka buta informasi, tidak mengetahui informasi harga ternak, terlebih lagi pada saat peternak memerlukan uang, sehingga ternak terjual harganya menjadi tidak wajar. Hal inilah yang menyebabkan gross margin peternak kurang maksimal, di lain pihak pedagang desa, pedagang besar dan jagal mendapatkan gross margin yang lebih besar, karena merekalah yang berhubungan langsung dengan pasar. Ironisnya harga daging sapi lokal di pasar-pasar tradisional tetap tinggi. Hal inilah yang melatarbelakangi penelitian untuk menelusuri apa saja yang membuat gross margin peternak kurang maksimal, dan bagaimana saluran pemasaran ternak sapi potong di Kabupaten Ogan Komering Ilir, serta menentukan 
strategi pemasaran yang tepat agar gross margin peternak dapat meningkat.

Tujuan penelitian ini adalah untuk mengidentifikasi saluran pemasaran sapi potong Ogan Komering Ilir, mengetahui berat taksir dan berat timbang ternak pedagang perantara, margin pemasaran dan gross margin peternak, pedagang desa, pedagang besar dan jagal, serta menentukan strategi pemasaran yang tepat agar gross margin peternak dapat meningkat.

\section{Materi dan Metode}

Penelitian ini dilaksanakan selama 2 (dua) bulan mulai awal Juli sampai dengan akhir Agustus 2011. Penelitian ini dilakukan di Kabupaten Ogan Komering Ilir, Propinsi Sumatera Selatan. Pengambilan lokasi dipilih tiga wilayah kecamatan secara purposive sampling yaitu Kecamatan Lempuing, Lempuing Jaya, dan Mesuji Raya, dengan pertimbangan bahwa ketiga wilayah kecamatan tersebut mempunyai populasi ternak sapi terbanyak yaitu Kecamatan Lempuing sebanyak 4.165 ekor, Lempuing Jaya sebanyak 3.895 ekor dan Mesuji Raya sebanyak 2.900 ekor, dari seluruh populasi ternak sapi Kabupaten Ogan Komering Ilir sebanyak 34.386 ekor (Dinas Peternakan Kabupaten Ogan Komering Ilir, 2010) dan juga didukung ketersediaan faktor penunjang yaitu adanya pasar hewan dan tempat pemotongan hewan (jagal).

Materi penelitian yang digunakan adalah sapi potong yang dijual peternak sejumlah 60 ekor (30 ekor jantan dan 30 ekor betina). Sampel diambil dari 3 kecamatan yang dipilih secara purposive, tiap kecamatan diambil sebanyak 20 ekor; pedagang desa dari 3 kecamatan, masing-masing kecamatan diambil 5 (lima) orang, kemudian sampel sapi masing-masing pedagang sebanyak 4 ekor terdiri 2 ekor jantan dan 2 ekor betina dipilih secara purposive; pedagang besar antar kabupaten sebanyak 5 (lima) orang di pasar hewan Kecamatan Lempuing pada hari pasaran, dengan mengambil sampel masing masing pedagang sebanyak 12 ekor terdiri 6 ekor jantan dan 6 ekor betina dipilih secara purposive; jagal sebanyak 5 orang yaitu di Kecamatan Lempuing 3 orang, Lempuing Jaya 1 orang dan Kayuagung 1 orang dengan mengambil sampel sebanyak 6 ekor sapi jantan yang diambil secara purposive; timbangan ternak dan kuesioner.

Penelitian dilaksanakan secara survei, pengamatan langsung dan wawancara pada peternak, pedagang desa, pedagang besar dan jagal dengan menggunakan kuesioner untuk memperoleh data primer meliputi identitas, profil, karakteristik usaha responden, berat taksir, berat timbang, harga beli ternak, harga jual ternak, biaya produksi dan biaya pemasaran. Pengambilan data primer lainnya dilakukan dengan menimbang ternak di tingkat peternak, pedagang desa, pedagang besar dan jagal. Data primer tersebut digunakan untuk mengetahui saluran pemasaran ternak, margin pemasaran dan gross margin peternak, pedagang desa, pedagang besar dan jagal.

Untuk mengidentifikasi saluran pemasaran ternak sapi potong di Kabupaten Ogan Komering Ilir dengan mengikuti alur pemasaran menggunakan analisis deskriptif; untuk mengetahui harga beli atau jual ternak per kilo gram berat hidup di peternak, pedagang perantara dan jagal diperoleh dari perbandingan antara harga beli atau jual ternak sapi (Rp/ekor) dengan berat hidup ternak sapi ( $\mathrm{kg}$ ), untuk mengetahui perbedaan berat taksir dengan berat timbang ternak digunakan uji $t$, untuk mengetahui perbedaan gross margin peternak, pedagang desa, pedagang besar dan jagal ditampilkan dalam bentuk tabel, kemudian dianalisis menggunakan one way ANOVA. Apabila terdapat perbedaan dilanjutkan uji Duncan dengan menggunakan program SPSS versi 17.

\section{Hasil dan Pembahasan}

\section{Profil responden}

Keberhasilan usaha peternak, pedagang desa, pedagang besar dan jagal sangat tergantung dari kemampuan dan kemauannya dalam mengelola usaha. Beberapa faktor yang turut berpengaruh meliputi umur, pekerjaan utama, jumlah anggota keluarga dan pengalaman.

Pada Tabel 1 dapat dilihat bahwa umur responden tergolong dalam usia produktif. Kinyua et al. (2011) menyatakan bahwa umur 44 tahun relatif muda dan energik dan cenderung membuat keputusan yang tegas dalam hal manajemen. Demikian juga pengalaman responden tergolong lama dalam menekuni profesinya. Menurut Suratiyah (2006), ditinjau dari aspek usia dan pengalaman maka semakin tua umur akan semakin berpengalaman, sehingga akan semakin baik dalam mengelola usahanya, tetapi di sisi lain semakin tua umurnya akan semakin turun kemampuan fisiknya, sehingga mereka akan membutuhkan bantuan tenaga kerja terutama dari keluarga.

Dilihat dari pekerjaan utama peternak adalah bertani yaitu kegiatan yang menyangkut proses produksi menghasilkan bahan kebutuhan manusia yang dapat berasal dari tumbuhan maupun hewan disertai dengan usaha-usaha untuk memperbarui, memperbanyak dan mempertimbangkan faktor ekonomis (Suratiyah, 2006). Pedagang dan jagal jual beli ternak sapi dan jual daging sapi adalah sebagai pekerjaan utama yaitu kegiatan di mana seluruh sumberdaya dan kemampuan yang mereka miliki dicurahkan pada profesinya. 
Tabel 1. Karakteristik responden (characteristics of respondent)

\begin{tabular}{|c|c|c|c|c|}
\hline Karakteristik (characteristic) & $\begin{array}{l}\text { Peternak } \\
(\text { farmer }) \\
(\mathrm{n}=60)\end{array}$ & $\begin{array}{c}\text { Pedagang desa } \\
\text { (village traders) } \\
(\mathrm{n}=15)\end{array}$ & $\begin{array}{l}\text { Pedagang besar } \\
(\text { wholesalers }) \\
(\mathrm{n}=5)\end{array}$ & $\begin{array}{c}\text { Jagal } \\
\text { (butchers) } \\
(\mathrm{n}=5)\end{array}$ \\
\hline Umur (tahun) & $42,62 \pm 7,24$ & $47 \pm 10,51$ & $54,2 \pm 4,76$ & $44 \pm 13,74$ \\
\hline \multicolumn{5}{|l|}{ Pekerjaan utama (\%) (main occupation (\%)) } \\
\hline Tani (farmer) & 100,00 & 13 , & 0 & 0 \\
\hline B & 0 & & 100,00 & 100,00 \\
\hline $\begin{array}{l}\text { Jumlah anggota keluarga (orang) (number of } \\
\text { household members (person)) }\end{array}$ & $4,6 \pm 0,72$ & $4,3 \pm 1,03$ & $5 \pm 1,0$ & $4 \pm 0,71$ \\
\hline Pengalaman (th) (experience (years)) & $12,53 \pm 3,59$ & $13,4 \pm 4,53$ & $20,2 \pm 3,42$ & $14,6 \pm 9,68$ \\
\hline
\end{tabular}

Rata-rata jumlah anggota keluarga responden sebanyak 4-5 orang. Tenaga kerja keluarga peternak dimanfaatkan untuk membantu usaha dalam pemeliharaan ternaknya, sedangkan tenaga kerja keluarga pedagang dan jagal yang tidak melanjutkan studinya berperan membantu dalam jual beli ternak atau menjual daging serta diharapkan sebagai penerus pekerjaan orang tuanya, tetapi tidak berperan bagi anggota keluarga yang masih belajar.

\section{Karakteristik usaha responden}

Karakteristik usaha responden meliputi kepemilikan ternak, jumlah pembelian ternak, jumlah pemotongan ternak dan skala usaha (Tabel 2). Kepemilikan ternak rata rata sebanyak 4 ekor. Hal ini menunjukkan bahwa peternak pada umumnya menjual ternaknya setelah memiliki lebih dari 3 ekor, karena peternak ingin menjaga agar usahanya tetap berjalan. Peternak dalam melaksanakan usahanya masih sebagai usaha sambilan (68,33\%). Hal ini karena peternak masih mempunyai usaha produktif lain yang lebih besar menyumbang pendapatan yaitu sebagai petani sawah dan petani kebun.

Pedagang desa dalam melaksanakan jual beli ternak rata-rata sebanyak 7 ekor/minggu. Hal ini menunjukkan bahwa mereka masih produktif dalam menekuni profesinya. Masa penampungan ternak sampai penjualan memerlukan waktu 3-7 hari, setelah 7 hari ternak habis terjual.

Pedagang besar melakukan transaksi sesuai dengan hari pasaran. Dalam satu minggu 2 kali melakukan transaksi pembelian ternak di pasar hewan yaitu pada hari senin di Pasar Hewan Tugu Jaya dan kamis di Pasar Hewan Tugu Mulyo. Mereka melakukan transaksi rata-rata sebanyak 25 ekor/minggu. Masa penampungan sampai penjualan ternak selama 2-4 hari dan mereka sudah mempunyai jaringan pemasaran ternak sendiri.

Jagal melakukan pemotongan sapi jantan rata-rata 9 ekor/minggu. Hal ini menunjukkan bahwa jagal berusaha maksimal memenuhi permintaan konsumen. Waktu yang diperlukan untuk menjual daging sampai habis selama 1-2 hari.

\section{Pemasaran ternak sapi}

Pemasaran ternak dimulai dari peternak sampai konsumen akhir dan pergerakannya melalui saluran pemasaran yang terdiri dari pedagang desa, pedagang besar dan jagal. Saluran I merupakan saluran pemasaran yang paling banyak dilalui dalam jual beli ternak sapi $(88,33 \%)$, karena saluran ini sudah lama terbangun secara alami dan sudah mengakar di kalangan peternak.

Pada Tabel 3 dapat dilihat bahwa margin pemasaran sapi jantan terbesar terjadi pada saluran I, saluran II dan III, sedangkan sapi betina pada saluran I dan saluran II. Hal ini terjadi karena saluran I banyak melibatkan pedagang perantara, di mana setiap pedagang perantara mengeluarkan biaya pemasaran dan mengharapkan gross margin yang maksimal, inilah yang menyebabkan margin pemasaran menjadi besar. Hal ini sesuai pendapat Nurhayati (2000); Arinto (2004); Sumpe (2007), bahwa semakin panjang rantai pemasaran maka semakin besar pula margin pemasarannya.

Pada Tabel 4 dapat dilihat bahwa harga ternak sapi potong pada saluran I paling rendah dibandingkan dengan saluran II dan III. Hal ini terjadi disebabkan oleh panjangnya saluran pemasaran, yang mengakibatkan posisi peternak menjadi tertekan. Pada saluran I melalui dua tingkat pedagang perantara yaitu pedagang desa dan pedagang besar, masing masing perantara mengeluarkan biaya pemasaran dan mereka menginginkan gross margin yang besar, akibatnya harga jual ternak di peternak menjadi rendah. Pada saluran II melalui satu tingkat pedagang perantara yaitu pedagang desa dan saluran III langsung dari peternak ke jagal. Semakin pendek saluran pemasaran maka semakin tinggi harga jual ternak di tingkat peternak, karena pedagang perantara yang terlibat semakin sedikit. Peternak yang bisa menjual langsung melalui saluran III atau II, mereka akan memperoleh harga yang tinggi. Hal ini hanya bisa terjadi apabila peternak menjual ternaknya ke pasar hewan, pedagang besar atau jagal.

Dari Tabel 5 dapat dilihat bahwa harga ternak jantan per kilogram berat hidup pada setiap saluran 
Tabel 2. Karakteristik usaha responden (characteristics of responden)

\begin{tabular}{|c|c|c|c|c|}
\hline $\begin{array}{l}\text { Karakteristik usaha responden (business } \\
\text { characteristics of respondent) }\end{array}$ & $\begin{array}{l}\text { Peternak } \\
(\text { farmer }) \\
(\mathrm{n}=60)\end{array}$ & $\begin{array}{c}\text { Pedagang Desa } \\
\text { (village traders) } \\
(\mathrm{n}=15)\end{array}$ & $\begin{array}{c}\text { Pedagang Besar } \\
(\text { wholesalers }) \\
(\mathrm{n}=5)\end{array}$ & $\begin{array}{c}\text { Jagal } \\
\text { (butchers) } \\
(\mathrm{n}=5)\end{array}$ \\
\hline $\begin{array}{l}\text { Kepemilikan ternak sapi (ekor) (ownership of beef } \\
\text { cattle (head)) }\end{array}$ & $4 \pm 0,96$ & - & - & - \\
\hline $\begin{array}{l}\text { Pembelian ternak sapi per minggu (ekor) (purchase } \\
\text { of beef cattle per week (head)) }\end{array}$ & - & $7 \pm 1,52$ & $25 \pm 3,97$ & - \\
\hline $\begin{array}{l}\text { Pemotongan ternak sapi per minggu (ekor) } \\
\text { (slaughter cattle per week (head)) }\end{array}$ & - & - & - & $9 \pm 2,95$ \\
\hline \multicolumn{5}{|l|}{ Skala usaha (\%) (scale enterprise (\%)) } \\
\hline Usaha pokok (main occupation) & 0 & 86,67 & 100,00 & 80,00 \\
\hline on branches) & 31,67 & 13,33 & 0 & 20,00 \\
\hline Usaha sambilan (sideline occupation) & 68,33 & 0 & 0 & 0 \\
\hline
\end{tabular}

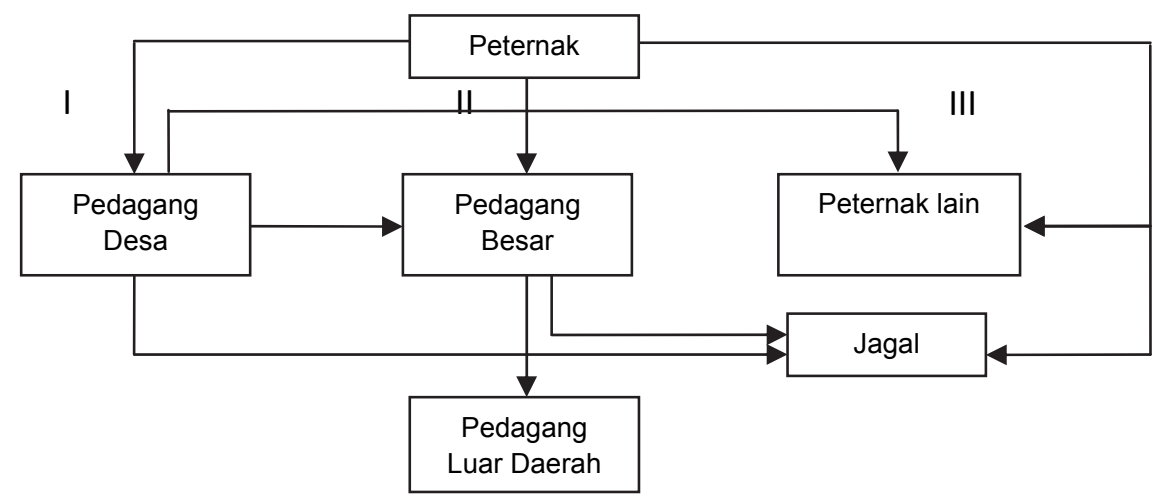

Gambar 1. Saluran pemasaran ternak sapi potong di Kabupaten Ogan Komering Ilir (marketing channels of beef cattle in Ogan Komering Ilir Regency).

Tabel 3. Margin pemasaran ternak sapi potong tiap saluran pemasaran (Rp/ekor) (marketing margins of beef cattle in marketing channels (Rp/head))

\begin{tabular}{|c|c|c|c|c|c|c|c|}
\hline \multirow{2}{*}{$\begin{array}{c}\text { Saluran } \\
\text { Pemasaran (marketing } \\
\text { channels) }\end{array}$} & \multicolumn{2}{|c|}{$\begin{array}{c}\text { Pedagang desa (vilage } \\
\text { traders) }\end{array}$} & \multicolumn{2}{|c|}{$\begin{array}{c}\text { Pedagang besar } \\
\text { (wholesalers) }\end{array}$} & \multirow{2}{*}{$\begin{array}{c}\begin{array}{c}\text { Jagal } \\
\text { (butchers) }\end{array} \\
\text { Jantan } \\
\text { (bull) }\end{array}$} & \multicolumn{2}{|c|}{ Jumlah (total) } \\
\hline & $\begin{array}{c}\text { Jantan } \\
\text { (bull) }\end{array}$ & $\begin{array}{l}\text { Betina } \\
(\text { cow })\end{array}$ & $\begin{array}{c}\text { Jantan } \\
\text { (bull) }\end{array}$ & & & $\begin{array}{c}\mathrm{Jan} \\
(b u\end{array}$ & \\
\hline salur & 2.082 .536 & 1.363 .393 & & 396 & 0 & 2.562 .83 & 789 \\
\hline & - & & & & 0 & 930. & \\
\hline Saluran III (channel III) & - & - & - & - & 0 & 0 & \\
\hline
\end{tabular}

Tabel 4. Harga ternak sapi potong tiap responden pada setiap saluran pemasaran (Rp/ekor) (beef cattle price in each respondent at each market chain (Rp/head))

\begin{tabular}{lrrrrr}
\hline \hline \multirow{2}{*}{ Responden (respondent) } & \multicolumn{2}{c}{ Saluran I (channel I) } & \multicolumn{2}{c}{ Saluran II (channel II) } & $\begin{array}{c}\text { Saluran III } \\
\text { (channel III) }\end{array}$ \\
\cline { 2 - 5 } & Jantan (bull) & Betina (cow) & Jantan (bull) & Betina (cow) & Jantan (bull) \\
\hline Pedagang desa (village traders) & 8.301 .144 & 6.376 .667 & - & - & - \\
Pedagang besar (wholesalers) & 10.383 .680 & 7.740 .060 & 9.933 .000 & 6.747 .003 & - \\
Jagal/konsumen (butchers/consumer) & $10.863,979$ & 8.238 .456 & 10.863 .979 & 8.238 .456 & 10.415 .000 \\
\hline
\end{tabular}

pemasaran lebih mahal dibandingkan dengan ternak sapi betina. Hal ini disebabkan antara lain, sapi jantan memiliki pertambahan berat badan harian relatif lebih baik dari pada sapi betina (Basuki, 2004), menghasilkan daging lebih banyak dan kandungan lemaknya lebih sedikit, prestise pembeli karena pengaruh penampilan dan keyakinan dalam melaksanakan hajat sapi jantan lebih dipilih, bagi pedagang sapi jantan lebih cepat terjual. Ditinjau dari sisi peraturan untuk dapat memotong sapi betina diperlukan birokrasi yang rumit dan memerlukan biaya tambahan.

Ternak yang diperjualbelikan dalam penentuan harga berdasarkan taksiran berat hidup (tidak 
Tabel 5. Harga ternak sapi potong di pedagang desa, pedagang besar dan jagal pada setiap saluran pemasaran (Rp/kg berat hidup) (beef cattle price at village traders, wholesalers and butchers on each marketing channel (Rp/kg live weight))

\begin{tabular}{lccccc}
\hline \hline & \multicolumn{2}{c}{ Saluran I (channel $)$} & \multicolumn{2}{c}{ Saluran II (channel II) } & $\begin{array}{c}\text { Saluran III } \\
\text { (channel III) }\end{array}$ \\
\cline { 2 - 6 } Responden (respondent) & $\begin{array}{c}\text { Jantan }(\text { bull }) \\
(\mathrm{n}=30)\end{array}$ & $\begin{array}{c}\text { Betina }(\text { cow }) \\
(\mathrm{n}=30)\end{array}$ & $\begin{array}{c}\text { Jantan }(\text { bull }) \\
(\mathrm{n}=30)\end{array}$ & $\begin{array}{c}\text { Betina }(\text { cow }) \\
(\mathrm{n}=30)\end{array}$ & $\begin{array}{c}\text { Jantan }(\text { bull }) \\
(\mathrm{n}=10)\end{array}$ \\
\hline $\begin{array}{l}\text { Pedagang desa (village } \\
\text { traders) }\end{array}$ & $20.558 \pm 1.175,8$ & $20.347 \pm 1.567,5$ & - & - & - \\
$\begin{array}{l}\text { Pedagang besar } \\
\text { (wholesalers) }\end{array}$ & $25.715 \pm 416,6$ & $24.603 \pm 1.151,2$ & $24.599 \pm 1.122,8$ & $21.446 \pm 817,1$ & - \\
$\begin{array}{l}\text { Jagal/konsumen } \\
\text { (butchers/consumer) }\end{array}$ & $26.904 \pm 841,7$ & $25.790 \pm 1.251,6$ & $26.904 \pm 841,7$ & $25.790 \pm 1.251,6$ & $25.792 \pm 833,6$ \\
\hline
\end{tabular}

Tabel 6. Berat taksir dan berat timbang ternak sapi potong ( $\mathrm{kg} / \mathrm{ekor}$ ) (weight estimation and weighing weight of beef cattle ( $\mathrm{kg} / \mathrm{head})$

\begin{tabular}{lcc}
\hline \hline \multicolumn{1}{c}{ Cara pengukuran (how tomeasure) } & Jantan (bull) & Betina (cow) \\
$(n=15)$ & $15)$ \\
\hline Taksiran (estimate) & $385,67 \pm 58,66$ & $309,17 \pm 37,07$ \\
Timbangan (scale) & $389,13 \pm 58,99$ & $313,40 \pm 37,13$ \\
\hline
\end{tabular}

ditimbang). Pedagang perantara akan mengamati ternak secara seksama agar memperoleh hasil taksiran berat yang akurat untuk menentukan harga ternak yang wajar. Terdapat selisih berat $3,47 \mathrm{~kg}$ untuk sapi jantan dan 4,23 kg untuk sapi betina, secara keseluruhan terdapat selisih berat kurang dari $5 \mathrm{~kg}$ sebagai faktor koreksi apabila terjadi kesalahan penaksiran.

Dari Tabel 7 dapat dilihat bahwa pendapatan peternak sapi jantan yang paling besar terdapat pada saluran III dan sapi betina terdapat pada saluran II. Pada kenyataannya keadaan ini sulit tercapai, karena saluran pemasaran ternak pada saluran I sudah lama terbangun dan telah mengakar pada sistim pemasaran ternak tradisional, sehingga untuk mengubah perilaku saluran pemasaran sangat sulit. Disamping itu jagal dan pedagang besar tidak ingin terlalu repot mencari ternak langsung ke peternak, keadaan ini hanya bisa terjadi di pasar hewan atau pedagang besar dan jagal bertempat tinggal di satu desa dengan peternak.

Dari tabel tersebut juga dapat dilihat bahwa gross margin responden pada sapi jantan yang paling besar berturut turut adalah jagal, pedagang desa dan pedagang besar, untuk sapi betina adalah pedagang desa dan pedagang besar. Setelah dilakukan analisis dengan one way ANOVA terhadap gross margin peternak, pedagang desa, pedagang besar dan jagal, terdapat perbedaan yang nyata $(\mathrm{P}<0,05)$, kemudian setelah diuji lanjut dengan uji Duncan terdapat perbedaan gross margin antara peternak dengan pedagang desa dan jagal, namun tidak berbeda dengan pedagang besar. Gross margin pedagang desa berbeda dengan pedagang besar dan jagal, demikian juga gross margin pedagang besar berbeda dengan jagal. Pada saluran I, gross margin jagal paling besar disebabkan pengaruh dari hasil penjualan tulang dan hasil ikutan lainnya. Gross margin pedagang desa juga besar karena mereka mengeluarkan biaya transportasi yang besar, ini sesuai dengan Kapimbi dan Teweldemedhin (2012), bahwa mereka juga terlibat dalam pemasaran paling tidak untuk menutupi biaya pemasaran. Jumlah ternak yang diperjualbelikan juga sedikit kurang lebih hanya 7 ekor/minggu, disamping itu mereka sangat dominan dalam melakukan negosiasi dengan peternak sehingga harga dapat dikendalikan, mereka juga mengambil sebagian keuntungan dari pedagang besar. Hal ini sesuai dengan pendapat Arinto (2004), pedagang desa dan blantik pasar menerima keuntungan yang lebih besar dari bagian biaya dalam marjin pemasaran. Selanjutnya dikatakan bahwa posisi perantara (pedagang desa) lebih kuat dari pada peternak, sehingga harga sangat ditentukan oleh perantara (pedagang desa). Gross margin pedagang besar paling kecil, tetapi karena ternak yang dijual per minggunya jumlahnya banyak yaitu 25 ekor, maka diperoleh total gross margin yang besar. Hal ini sesuai dengan pendapat Arinto (2004), bahwa pedagang besar mendapat keuntungan paling kecil padahal resiko yang ditanggung paling besar.

\section{Kebijakan strategi pemasaran}

Setelah memahami masalah yang dihadapi peternak, maka untuk meningkatkan gross margin perlu diambil kebijakan strategi pemasaran yang tepat. Adapun kebijakan strategi pemasaran tersebut 
Tabel 7. Analisis usaha dan margin pemasaran ternak sapi potong di setiap saluran pemasaran (business analysis and marketing margins beef cattle every marketing channel)

\begin{tabular}{|c|c|c|c|c|c|}
\hline \multirow{2}{*}{$\begin{array}{l}\text { Responden dan komponen margin } \\
\text { (responden and components } \\
\text { margin) }\end{array}$} & \multicolumn{2}{|c|}{ Saluran I (channel I) } & \multicolumn{2}{|c|}{ Saluran II (channel II) } & \multirow{2}{*}{$\begin{array}{c}\begin{array}{c}\text { Saluran III } \\
\text { (channel } \\
\text { III) }\end{array} \\
\text { Jantan (bull) }\end{array}$} \\
\hline & Jantan (bull) & $\begin{array}{c}\text { Betina } \\
(\text { cow })\end{array}$ & Jantan (bull) & $\begin{array}{c}\text { Betina } \\
\text { (cow) }\end{array}$ & \\
\hline \multicolumn{6}{|l|}{$\begin{array}{l}\text { Peternak (farmers) } \\
\text { Komponen (components): }\end{array}$} \\
\hline Komponen (components): & & & & & \\
\hline \multicolumn{6}{|l|}{ Penerimaan (a) (revenue (a)) } \\
\hline Penjualan sapi (sale of cattle) & 8.301 .144 & 6.376 .667 & 9.933 .000 & 6.747 .003 & 10.415 .000 \\
\hline Biaya-biaya (b) (costs (b)) & 7.427.311 & 5.996 .917 & 7.427 .311 & 5.996 .917 & 7.427 .311 \\
\hline Beli sapi bakalan (cattle & 5.397 .811 & 3.731 .667 & 5.397 .811 & 3.731 .667 & 5.397 .811 \\
\hline purchase) & 1.775 .000 & 1.605 .500 & 1.775 .000 & 1.605 .500 & 1.775 .000 \\
\hline Pakan (feed) & 245.500 & 659.750 & 245.500 & 659.750 & 245.500 \\
\hline \multicolumn{6}{|l|}{ Obat-obatan (veterinary costs) } \\
\hline Gross margin (a-b) & $\begin{array}{r}873.833 \\
(14,00 \%)\end{array}$ & $\begin{array}{r}379.750 \\
(21,23 \%)\end{array}$ & $\begin{array}{r}2.005 .689 \\
(33,21 \%)\end{array}$ & $\begin{array}{r}750.086 \\
(35,92 \%)\end{array}$ & $\begin{array}{r}2.987 .689 \\
(44,63 \%)\end{array}$ \\
\hline \multicolumn{6}{|l|}{ Pedagang desa (village traders) } \\
\hline Penjualan (a) (sale (a)) & $10.383-680$ & 7.740 .060 & - & - & \\
\hline Biaya-biaya (b) (costs $(b))$ & 8.600 .467 & 6.675 .990 & & & \\
\hline Harga beli (purchasing price) & 8.301 .144 & 6.376 .667 & & & \\
\hline $\begin{array}{l}\text { Biaya transportasi } \\
\text { (transportation costs) }\end{array}$ & 177.667 & 177.667 & & & \\
\hline Upah tenaga kerja (labor wages) & 121.656 & 121.656 & & & \\
\hline Gross margin (a-b) & $\begin{array}{r}1.783 .213 \\
(28,57 \%) \\
\end{array}$ & $\begin{array}{r}1.064 .070 \\
(59,49 \%) \\
\end{array}$ & & & \\
\hline \multicolumn{6}{|l|}{ Pedagang besar (wholesalers) } \\
\hline Penjualan (a) (sale (a)) & 10.863 .979 & 8.238 .456 & 10.863 .979 & 8.238 .456 & \\
\hline Biaya-biaya (b) $($ costs $(b))$ & 10.537 .243 & 7.893 .623 & 10.086 .563 & 6.900 .566 & \\
\hline Harga beli (purchasing price) & 10.383 .680 & 7.740 .060 & 9.933 .000 & 6.747 .003 & \\
\hline $\begin{array}{l}\text { Biaya transportasi } \\
\text { (transportation costs) }\end{array}$ & 80.187 & 80.187 & 80.187 & 80.187 & \\
\hline Upah tenaga kerja (labor wages) & 73.376 & 73.376 & 73.376 & 73.376 & \\
\hline Gross margin (a-b) & $\begin{array}{l}326.736 \\
(5,26 \%)\end{array}$ & $\begin{array}{r}344.833 \\
(19,28 \%)\end{array}$ & $\begin{array}{r}777.416 \\
(12,87 \%)\end{array}$ & $\begin{array}{r}1.337 .890 \\
(64,08 \%)\end{array}$ & \\
\hline \multicolumn{6}{|l|}{ Jagal (butchers) } \\
\hline Penjualan (a) (sale (a)) & $14.489 .959^{*}$ & - & $14.489 .959^{*}$ & - & $14.489 .959 *$ \\
\hline Biaya-biaya (b) $(\operatorname{costs}(b))$ & 11.233 .061 & & 11.233 .061 & & 10.784 .082 \\
\hline Harga beli (buying price) & 10.863 .979 & & 10.863 .979 & & 10.415 .000 \\
\hline Pajak potong (tax of slaughter) & 15.000 & & 15.000 & & 15.000 \\
\hline $\begin{array}{l}\text { Biaya transportasi } \\
\text { (transportation costs) }\end{array}$ & 100.082 & & 100.082 & & 100.082 \\
\hline Upah tenaga kerja (labor wages) & 254.000 & & 254.000 & & 254.000 \\
\hline Gross margin (a-b) & $\begin{array}{r}3.256 .898 \\
(52,19 \%)\end{array}$ & & $\begin{array}{r}3.256 .898 \\
(53,92 \%)\end{array}$ & & $\begin{array}{r}3.706 .877 \\
(55,37 \%)\end{array}$ \\
\hline $\begin{array}{l}\text { Margin pemasaran ternak (marketing } \\
\text { margin of cattle) }\end{array}$ & 2.562 .835 & 1.861 .789 & 930.979 & 1.491 .453 & \\
\hline Total gross margin & 6.240 .680 & 1.788 .653 & 6.040 .003 & 2.087 .976 & 6.694 .566 \\
\hline
\end{tabular}

* Konversi harga jual (convertion of selling price).

adalah kebijakan saluran pemasaran, kebijakan harga, dan kebijakan gross margin.

Kebijakan saluran pemasaran. Merupakan keputusan memilih saluran pemasaran yang paling menguntungkan diantara 3 (tiga) saluran pemasaran yang ada. Untuk jangka pendek peternak masih memerlukan saluran pemasaran I. Saluran ini sudah terbangun begitu lama dan sudah mengakar di sistem pemasaran ternak yang ada. Selain itu peternak masih menaruh kepercayaan yang tinggi kepada pedagang desa untuk membeli ternaknya. Untuk jangka panjang saluran III dapat dipilih sebagai saluran utama dalam pemasaran ternaknya, karena saluran ini memberikan dampak yang baik 
bagi peternak dan jagal. Pada saluran III, peternak maupun jagal dapat memperoleh gross margin yang maksimal, namun dalam prakteknya sangat sulit, karena masing-masing punya persyaratan yang baku. Pihak jagal meminta suplai ternak yang kontinyu dengan standar yang relatif seragam. Persyaratan ini oleh peternak sangat berat, peternak hanya mampu menyediakan dalam jumlah terbatas dan standar yang tidak seragam. Di sinilah perlu peran Dinas Peternakan untuk menjembatani kedua kepentingan tersebut dengan memfasilitasi untuk mengadakan perjanjian kerja sama (MOU). Hai ini dapat dicapai dengan membentuk kelompok usaha penggemukan yang bertujuan untuk memenuhi permintaan jagal tersebut, ini sesuai dengan pendapat Zivenge dan Karavina (2012), bahwa petani peternak didorong untuk bergabung dalam kelompok atau koperasi agar dapat meningkatkan kesempatan mereka dalam mengakses input produksi dan pemerintah harus memberikan penyuluhan kepada kelompok untuk meningkatkan produksi. Jika hal ini terealisasi maka saluran III akan berjalan sangat dominan dan menggantikan saluran I, akhirnya berdampak pada peningkatan gross margin peternak yang maksimal.

Kebijakan harga. Merupakan kebijakan untuk menentukan tingkat harga maupun stabilitas harga dalam pemasaran, karena harga sangat berpengaruh terhadap keputusan peternak. Semakin tinggi harga produk peternakan akan memicu gairah peternak untuk meningkatkan produksinya guna memenuhi pasar. Dalam kenyataannya penentuan harga jual di peternak masih dikendalikan oleh pedagang desa. Peternak belum memiliki kemampuan menaksir dan tidak memiliki informasi pasar. Sesuai dengan pendapat Rahmanto (2005), ketergantungan peternak terhadap jasa pedagang pengumpul dalam pemasaran ternaknya cukup tinggi, meskipun tersedia fasilitas pasar yang memadai. Hal ini disebabkan oleh beberapa faktor, diantaranya: tingkat skala usaha peternak relatif kecil, sehingga pengeluaran biaya angkutan ke pasar tidak efisien; peternak tidak menguasai cukup pengetahuan mengenai kondisi pasar; transaksi didasarkan pada taksiran pembeli, tidak ada patokan tertentu yang jelas dalam penentuan harga, seperti berat ternak dan indikator-indikator yang terukur lainnya sehingga melemahkan posisi tawar peternak; adanya blantik dadung sebagai makelar di pasar yang berpotensi mengurangi pendapatan peternak.

Arinto (2004) menyatakan bahwa peternak kurang diuntungkan dalam pemasaran terutama karena kebutuhan uang, sehingga terpaksa sapi dijual sebelum mencapai berat dan harga tertinggi serta harga sapi di pasar ditetapkan oleh pedagang. Pasar hewan lebih banyak memberi manfaat kepada pedagang dari pada peternak. Pembagian ke- untungan dalam lembaga pemasaran sapi tidak merata sesuai dengan biaya pemasaran yang dikeluarkan. Untuk mengatasi hal tersebut perlu diambil kebijakan strategi harga oleh Dinas Peternakan, dengan memperhatikan pemerataan gross margin bagi peternak, pedagang desa, pedagang besar dan jagal dengan jalan: memberi informasi, membina petugas, dan memberi bantuan.

Pemberian informasi harga pasar, margin pemasaran, dan gross margin di setiap tingkat kepada peternak melalui pembinaan kelompok sesuai dengan pendapat Musemwa et al. (2010), bahwa informasi yang tersedia, dukungan layanan dan teknologi harus selalu dapat diakses oleh pengguna. Selanjutnya dikatakan, pengembangan pengolahan agroindustri lokal dan pelatihan petani patut mendapatkan perhatian.

Pembinaan petugas Unit Pelaksana Teknis Daerah, Unit Layanan Inseminasi Buatan dan Kelompok, tentang pentingnya informasi pasar, permintaan dan suplai ternak secara kontinyu sesuai dengan pendapat Musemwa et al. (2010), bahwa pendekatan terpadu akan memungkinkan dalam mendukung sistem pemasaran ternak yang efisien. Hal ini memerlukan upaya bersama oleh pemerintah, peternak, organisasi produsen, dan pedagang perantara.

Pemberian bantuan timbangan ternak kepada kelompok dimaksudkan agar peternak mengetahui berat timbang ternak sebagai acuan untuk menentukan harga jual. Dengan mengetahui berat timbang ternak, peternak dapat menentukan harga jual berdasarkan biaya produksi, sehingga gross margin peternak dapat maksimal.

Kebijakan gross margin. Salah satu tujuan peternak melakukan usaha peternakan adalah untuk mendapatkan gross margin yang maksimal dengan pemberian harga input dan output yang menguntungkan peternak melalui sapta usaha peternakan. Kenyataannya peternak masih belum mampu meningkatkan gross margin-nya secara maksimal, karena ada beberapa kendala antara lain: belum ada standar baku harga ternak yang ditetapkan oleh pihak yang berwenang sehingga semuanya diserahkan pada mekanisme pasar; peternak tidak bisa menaksir berat ternak sehingga dalam pemasaran mereka mempercayakan kepada pedagang dan kesempatan ini dimanfaatkan oleh pedagang untuk menekan harga serendah mungkin; peternakan rakyat masih merupakan usaha sambilan sehingga belum melakukan penghitungan secara benar biaya produksi yang dikeluarkan selama pemeliharaan; peternak tidak berani membawa ternaknya ke pasar hewan karena biaya transportasi tinggi, kuatir ternaknya tidak terjual, takut tidak dibayar, sehingga keadaan ini juga dimanfaatkan oleh pedagang desa untuk menekan harga. 
Untuk mengatasi kendala tersebut diperlukan bimbingan dan pembinaan oleh Dinas Peternakan kepada peternak yaitu: analisis usaha sapi potong, pembentukan kelompok, perubahan paradigma, dan pemberian jaminan.

Analisis usaha sapi potong perlu dilakukan dengan harapan peternak dapat memahami aspek teknis dan ekonomi sehingga dapat memperbaiki tingkat pendapatan sesuai dengan potensi wilayah, dengan cara meminimalkan biaya produksi dan memaksimalkan hasil produksi dengan asumsiasumsi yang sesuai dengan potensi wilayah (kearifan lokal).

Pembentukan kelompok usaha ternak, yang difokuskan masing-masing pada kelompok usaha budidaya pembibitan dan kelompok usaha penggemukan sapi sesuai dengan pendapat Zivenge dan Karavina (2012), bahwa peternak didorong untuk bergabung dalam kelompok atau koperasi agar dapat meningkatkan kesempatan mereka dalam mengakses input produksi.

Paradigma skala usaha peternak perlu diubah, yang semula beternak sebagai usaha sambilan ditingkatkan menjadi cabang usaha bahkan beternak sebagai usaha pokok. Pemberian jaminan pemasaran dapat dilakukan dengan memfasilitasi peternak untuk mengadakan kerja sama (MOU) dengan pihak jagal atau pedagang besar.

\section{Kesimpulan}

Saluran pemasaran ternak di Kabupaten Ogan Komering Ilir ada 3 saluran. Saluran pemasaran I mempunyai margin pemasaran terbesar yaitu Rp2.562.835,-/ekor, hal ini membuktikan bahwa semakin panjang saluran pemasaran semakin besar margin pemasaran. Tidak ada perbedaan antara berat taksir dan berat timbang ternak. Selisih berat taksir dibandingkan berat timbang ternak kurang dari $5 \mathrm{~kg} /$ ekor yaitu sapi jantan sebesar 3,47 kg/ekor dan sapi betina $4,23 \mathrm{~kg} / \mathrm{ekor}$. Hal ini menunjukkan bahwa pedagang dan jagal sangat memahami dalam melakukan penaksiran berat ternak sapi potong, namun sebaliknya bagi peternak belum mampu. Terdapat perbedaan gross margin antara peternak dengan pedagang desa dan jagal, namun tidak dengan pedagang besar. Terdapat perbedaan gross margin antara pedagang desa dengan pedagang besar dan jagal, demikian juga antara pedagang besar dan jagal. Gross margin jagal paling besar, kemudian disusul pedagang desa, peternak dan pedagang besar. Oleh karena itu perlu dilakukan pendekatan dan kerjasama dengan Dinas Peternakan Kabupaten Ogan Komering Ilir agar melakukan inventarisasi kelompok sasaran baik kelompok budidaya maupun kelompok penggemukan dan melakukan sosialisasi tentang hasil penelitian ini kepada kelompok sasaran tersebut. Pemasaran ternak yang selama ini telah berjalan dibiarkan berjalan seperti semula, sembari melakukan pembinaan secara intensif kepada kelompok sasaran. Setelah kelompok sasaran memahami permasalahan yang dihadapi, selanjutnya kelompok didampingi petugas untuk melaksanakan anjuran dan bimbingan dari Dinas Peternakan terutama dalam pelaksanaan kebijakan strategi pemasaran, kelompok sasaran juga harus difasilitasi untuk mengadakan kerjasama (MOU) dengan pihak jagal agar gross margin-nya dapat maksimal.

\section{Daftar Pustaka}

Anonimus. 2009. Profil Peternakan Kabupaten Ogan Komering Ilir. Dinas Peternakan Kabupaten Ogan Komering Ilir, Kayuagung.

Anonimus. 2011. Rilis hasil awal pspk 2011. Kementerian Pertanian-Badan Pusat Statistik. Available at http://www.Ditjennak. deptan.go.id. Accession date: 27 November, 2011.

Arinto. 2004. Usaha dan Efisiensi pemasaran sapi potong di wilayah pembibitan dan pembesaran (Studi kasus di Kabupaten Grobogan). Disertasi S3. Universitas Gadjah Mada, Yogyakarta.

Basuki, P. 2004. Ilmu Ternak Kerja. Fakultas Peternakan, Universitas Gadjah Mada, Yogyakarta.

Dinas Peternakan Kabupaten Ogan Komering Ilir. 2010. Statistik Peternakan. Kayuagung.

Kapimbi, Y. and M. Y. Teweldemedhin. 2012. Analysis of factors determining catle marketing of communal famers in Namibia : case study from Kunene. J. Dev. Agric. Econ. 4: 169-177.

Kinyua, K. G., G. A. Yakub, N. B. Kamau and H. K. Bett. 2011. Livestock marketing decisions among pastoral communities: The influence of cattle rustling in Baringo District, Kenya. J. Dev. Manag. Agric. 1: 123-137.

Musemwa, L., A. Mushunje, M. Chimonyo and C. Mapiye. 2010. Low cattle market off-take rates in communal production systems of South Africa : Causes and mitigation strategies. J. Sus. Dev. in Africa 12: 209-225.

Nurhayati. 2000. Analisis efisiensi pemasaran ternak sapi siap potong di Kabupaten Grobogan. Tesis. Program Pasca Sarjana Universitas Gadjah Mada. Yogyakarta.

Rahmanto, B. 2005. Analisis Usaha Peternakan Sapi Potong Rakyat. Pusat Penelitian dan Pengembangan Sosial Ekonomi Pertanian. Jakarta. 
Rianto, E. dan E. Purbowati. 2010. Panduan Lengkap Sapi Potong. Cetakan ke 2. Penebar Swadaya. Jakarta.

Sumpe, I. 2007. Efisiensi pemasaran ternak sapi Bali di Kabupaten Manokwari. Tesis. Universitas Gadjah Mada, Yogyakarta.
Suratiyah, K. 2006. Ilmu Usaha Tani. Penebar Swadaya. Jakarta.

Zivenge, E. and C. Karavina. 2012. Analysis of factors influencing market channel access by communal horticulture farmers in chinamora District, Zimbabwe. J. Dev. Agric. Econ. 4: 147-150. 